\title{
PENGARUH KOMPOS LIMBAH SAGU TERHADAP BAWANG MERAH (Allium ascalonicum L.), DAN KARAKTERISTIK SIFAT FISIK TANAH SERTA POPULASI CACING TANAH (Lumbriscus terestris) DILAHAN KERING MUSIM KEMARAU
}

\section{THE INFLUENCE OF SAGO WASTE COMPOST TO THE GROWTH AND PRODUCTION OF RED ONION (Allium ascalonicum L.), AND THE CHARACTERIZATION OF THE PHYSICAL PROPERTIES OF SOIL, AS WELL ASEARTHWORM POPULATION (Lumbriscus terestris) ON DRYLAND OFDRY SEASON}

\author{
Muhammad Anang Firmansyah* dan Titin Apung Atikah** \\ * Balai Pengkajian Teknologi Pertanian Kalimantan Tengah \\ ** Universitas Palangka Raya
}

\begin{abstract}
ABSTRAK
Pemanfaatan limbah sagu sebagai sumber bahan organik yaitu kompos akan memberikan nilai positif baik bagi tanaman maupun produktivitas tanah dan mengurangi biaya pembelian pupuk kandang ayam yang semakin mahal. Penelitian dilakukan di lahan kering di musim kemarau pada petakan lahan bawang merah varietas tajukdengan menggunakan perlakuan dosis kompos limbah sagu. Perlakuan dosis kompos limbah sagu antara lain KS $0=$ kontrol, KS $1=35 \mathrm{t} / \mathrm{ha}$, KS $2=70 \mathrm{t} / \mathrm{ha}$ dan KS $3=105 \mathrm{t} / \mathrm{ha}$. Hasil menunjukkan tidak ada perbedaan nyata antar perlakuan terhadap parameter pertumuhan bwang merah umur 2 MST dan 4 MST. Namun pada parameter produksi kering menunjukkan bahwa perlakuan KS 3 berbeda naya dengan KS 0. Masing-masing 11,56 t/ha dibandingkan 9,61 t/ha. Perlakuan dosis kompos limbah sagu juga berpengaruh baik terhadap penurunan nilai bobot isi tanah, meningkatkan kadar air tanah dan juga porositas tanah. Hal ini terkait dengan makin meningkatnya dosis kompos limbah sagu maka makin meningkatkan jumlah populasi cacing tanah pada berbagai kedalaman tanah. Pada kedalaman 0-15 cm jumlah populasi cacing tanah tertinggi pada KS 3 mencapai 1.077 ekor $/ 2 \mathrm{~m}^{2}$ sedangkan KS 0 hanya 309 ekor $/ 2 \mathrm{~m}^{2}$.
\end{abstract}

Kata kunci : Allium ascalonicumL, kompos, cacing tanah, lahan kering.

\begin{abstract}
The utilization of sago waste as a source of organic material, namely compost will provide positive values for both plants and soil productivity and reduce the cost of purchasing chicken manure which is increasingly expensive. Research conductedon dry land in the dry seasonat a land plot of header/ tajuk varieties red onionusing the treatment of sago waste compost dosage. The treatment of sago waste compost doses, among others KS $0=$ control, KS $1=35$ $\mathrm{t} / \mathrm{ha}$, KS $2=70 \mathrm{t} / \mathrm{ha}$ dan KS $3=105 \mathrm{t} / \mathrm{ha}$. The results showed no significant differences between treatments on the growth parameters of red onion aged 2 MST and 4 MST. However, the dry production parameters show that KS treatment differs only with KS 0 . Respectively 11,56 t/ha compared to $9,61 \mathrm{t} / \mathrm{ha}$. The treatment of sago waste compost dosage also has a good effect on decreasing the value of soil bulk density, increasing soil water content and also soil porosity. It is associated with the increased dose of sago waste compost then further increase the number of earthworm populations at different depths in the soil. At a depth of $0-15 \mathrm{~cm}$ the highest population of earthworms at KS 3 reached $1,077 / 2 \mathrm{~m}^{2}$ while KS 0 is only $309 / 2 \mathrm{~m}^{2}$.
\end{abstract}

Keywords: Allium ascalonicumL, compost, earthworms, dry land. 


\section{PENDAHULUAN}

Beberapa varietas tanaman bawang merah (Allium ascalonicum L.) yang berasal dari dataran tinggi maupun menengah mampu beradaptasi dengan baik di dataran rendah (Kusuma et al. 2009), di tanah Alluvial (Firmansyah et al. 2015; Sumarni et al. 2012), tanah pasir pantai (Swasono 2012), di lahan bergambut dan gambut (Satsijati \& Koswara 1993; Firmansyah et al. 2014).

Varietas bawang merah yang telah ditanam di Kalimantan Tengah sejak tahun 2012 antara lain: Super Philip, Thailand, Bima Brebes, Pikatan, Katumi, Mentes, Sembrani, Manjung, Maja Cipanas, Trisula (Firmansyah dan Anto, 2013; Firmansyahet al, 2014). Beberapa tahun terakhir mulai masuk varietas Tajuk (Thailand Nganjuk) yang umumnya memiliki umbi relatif banyak namun berukuran umbi lebih kecil. Hal ini kemungkinan besar pengadaan benih bawang merah yang disukai petani bawang merah di Kalimantan Tengah tidak tersedia dipasaran.Karakter jumlah umbi bawang merah banyak dipengaruhi oleh faktor genetik dan sedikit oleh faktor lingkungan (Budianto et al., 2009).Jumlah anakan ada kaitannya dengan ukuran umbi bawang merah, bawang merah yang memiliki ukuran umbi besar maka jumlah anakannya akan lebih sedikit (Basuki 2005 dalam Kusmana et al. 2009).

Pemberian bahan organik berupa pupuk kandang ayam, nampaknya memberikan hasil yang baik bagi produksi bawang merah, namun harga pupuk kandang ayam yang tinggi merupakan kendala bagi petani. Saat ini harga pupuk kandang per zak pakan ayam mencapai Rp. 28.000,-. Hal ini perlu dipikirkan mengganti jenis pupuk organik yang lebih murah, yaitu limbah ampas dari pabrik pengolahan tepung sagu. Dengan membuat kompos dari limbah sagu ini maka akan diperoleh jenis bahan organik yang murah tanpa membeli.

Kompos secara umum akan memberikan dampak yang baik terhadap kesuburan tanah dan produksi tanaman. Begitu juga peranannya dalam memperbaiki sifat fisika tanah maupun menyediakan bahan makanan yang diperlukan oleh cacing tanah. Namun untuk jenis kompos limbah sagu ini belum dilakukan penelitian di lahan bawang merah, sehingga perlu diidentifikasi dengan lebih detil.

Hipotesis penelitian ini adalah semakin tinggi dosis kompos limbah sagu sampai pada dosis tertentu yang diberikan ke pertanaman bawang merah, maka akan 
meningkatkan produksi, memperbaiki sifat fisik tanah dan meningkatkan populasi cacing tanah dibandingkan tanpa pemberian kompos limbah sagu.

Tujuan penelitian ini untuk mengetahui dosis kompos limbah sagu terhadap pertumbuhan dan produksi bawang merah varietas Tajuk, serta dampaknya terhadap sifat fisik tanah dan populasi cacing tanah.

\section{METODOLOGI}

Penelitian dimulai pada akhir bulan April 2018.Diawali dengan pembuatan kompos limbah sagu, awal bulan Juli 2018 dilanjutkan penanaman bawang merah varietas Tajuk hingga panen pada bulan September 2018.

Pembuatan kompos limbah sagu menggunakan 10 bagian limbah sagu dicampur 2 bagian pupuk kandang dan disusun secara berlapis lapis dimana setiap lapisan ditaburi dedak dan bioaktivator EM-4. Setelah tersusun dengan ketinggian 0,75 $\mathrm{m}$ dan panjang 1,5 $\mathrm{m}$ dengan lebar 1 meter maka ditutup terpal. Setiap satu bulan sekali tumpukan diaduk rata.

Penelitian ini menggunakan RAK4x3, dimana perlakuannya adalah dosis kompos limbah sagu dan diulang tiga kali. Perlakuan dosis limbah sagu kondisi lembab, antara lain: KS $0=$ kontrol, KS 1
$=35 \mathrm{t} / \mathrm{ha}, \mathrm{KS} 2=70 \mathrm{t} / \mathrm{ha}$, dan KS $3=105$ t/ha. Petak yang digunakan berukuran $1 \mathrm{x}$ $2 \mathrm{~m}$, dengan ketinggian $20 \mathrm{~cm}$. Pupukdasar yang digunakan adalah dolomit 0,5 t/ha, NPK 16:16:16 $400 \mathrm{~kg} / \mathrm{ha}$, SP 36200 kg/ha. Pupuk susulan dilakukan dua kali yaitu pada umur 15 HST dan 30 HST masing-masing menggunakan NPK 16:16:16 sebanyak $200 \quad \mathrm{~kg} / \mathrm{ha}$. Pengendalian OPT menggunakan Pestisida secara rutin setiap 3 hari sekali. Panen dilakukan pada umur 56 HST.

Parameter yang diamati meliputi pertumbuhan tanaman bawang merah yaitu tinggi tanaman, jumlah daun dan jumlah anakan pada umur 15 dan 30 HST. Parameter panen meliputi berat panen kering per hektar. Konversi dari panen per petak dengan asumsi $70 \%$ setelah susut kadar air dan juga efisiensi lahan $70 \%$. Parameter lainnya adalah pada sifat fisik tanah yaitu bobot isi, kadar air berdasar berat dan volume dan porositas tanah. Sifat fisik tanah diambil di dalam satuan percobaan pada 3 lapisan yaitu 0-5 cm, 5$10 \mathrm{~cm}$ dan $10-15 \mathrm{~cm}$. Parameter populasi cacing tanah diamati dari luasan $25 \times 25 \mathrm{~cm}$ lalu dikonversi ke luasan petak percobaan. Populasi cacing tanah ini diamati pada setiap satuan percobaan.

Guna melihat pengaruh antar perlakuan pada pertumbuhan dan produksi 
bawang merah maka digunakan Uji jarak Berganda Duncan pada taraf 5\%. Untuk parameter karakterisasi sifat fisik tanah dan juga populasi cacing tanah menggunakan nilai tengah setiap paramater yang diukur.

\section{HASIL DAN PEMBAHASAN}

\section{Pertumbuhan dan Produksi Bawang}

\section{Merah}

Berdasarkan data pertumbuhan bawang merah varietas Tajuk menunjukkan tidak terdapat perbedaan antar perlakuan pada parameter yang diamati (Tabel 1). Ada kecenderungan bahwa jumlah daun yang banyak akan diikuti oleh jumlah anakan yang banyak, pada KS0 jumlah daun 35,67 helai memiliki jumlah anakan 9,58, begitu pula pada KS 2 jumlah daun 38,40 helai dan jumlah anakannya mencapai 9,60. Jumlah daun dapat diduga terkait jumlah anakan. Semakin banyak jumlah anakan, maka jumlah daun semakin banyak (Putrasamedja, 1990). Limbongan dan Monde (1999) jumlah umbi yang dihasilkan tanaman bawang merah terkait erat dengan jumlah daun. Jumlah daun yang banyak akan menghasilkan fotosintat yang banyak. Namun demikian pada seluruh parameter yang diamati terlihat perlakuan KS 2 memiliki nilai melebihi dari KS 0 (kontrol). Aliudin et al. (1990) menyatakan bahwa tinggi tanaman merupakan salah satu indikator pertumbuhan tanaman, namun demikian tinggi tanaman tidak berkorelasi dengan hasil.

Tabel 1. Parameter tinggi tanaman, jumlah daun dan jumlah anakan bawang merah Tajuk umur 2 dan 4 MST.

\begin{tabular}{|c|c|c|c|c|c|c|}
\hline \multirow{2}{*}{ Perlakuan } & \multicolumn{2}{|c|}{ Tinggi Tanaman (cm) } & \multicolumn{2}{c|}{ Jumlah Daun } & \multicolumn{2}{c|}{ Jumlah Anakan } \\
\cline { 2 - 7 } & 2 MST & 4 MST & 2 MST & 4 MST & 2 MST & MST \\
\hline KS 0 & 28,20 & 34,98 & 24,53 & 35,67 & 6,87 & 9,58 \\
KS 1 & 27,20 & 37,47 & 22,13 & 31,27 & 6,93 & 8,40 \\
KS 2 & 29,60 & 39,20 & 24,20 & 38,40 & 7,53 & 9,60 \\
KS 3 & 28,00 & 39,67 & 21,53 & 32,47 & 6,53 & 8,53 \\
\hline
\end{tabular}

Keterangan: Huruf yang sama pada kolom yang sama tidak berbeda nyata pada uji DMRT taraf $5 \%$.

Sumiati (1996) peningkatan jumlah daun maksimum akan berpengaruh dengan semakin banyak daun yang terbentuk sehingga daun akan menghasilkan fotosintat semakin tinggi untuk mendukung pertumbuhan dan perkembangan tanaman.

Perlakuan kompos nampaknya berpengaruh pada produksi kering bawang merah varietas Tajuk pada umur panen 55 
HST (Gambar 1). Perlakuan kompos tertinggi yaitu KS 3 berpengaruh nyata terhadap produksi kering mencapai 11,56 t/ha dibandingkan KS 0 yang hanya mencapai 9,61 t/ha. Hal ini menunjukkan bahwa untuk memperoleh hasil nyata terhadap produksi bawang merah yang menggunakan kompos limbah sagu, maka dosis yang digunakan mencapai $105 \mathrm{t} / \mathrm{ha}$. Hal ini kemungkinan disebabkan kompos limbah sagu memiliki kandungan hara rendah, tidak setinggi pupuk kandang ayam yang sering digunakan petani bawang merah di Palangka Raya. Dosis pupuk kandang ayam untuk bawang merah di Palangka Raya sekitar 5-10 t/ha. Selain itu kompos limbah sagu yang diaplikasikan memiliki sifat slow release artinya unsur hara yang terlepas yang tersedia untuk tanaman cenderung lambat. Sehingga diperkirakan efek residu dari kompos limbah sagu ini akan lama berfungsi untuk meningkatkan kesuburan tanah. Syahtria et al. (2016) pemberian kompos limbah sagu mampu meningkatkan pertumbuhan pada pembibitan tanaman kelapa sawit.

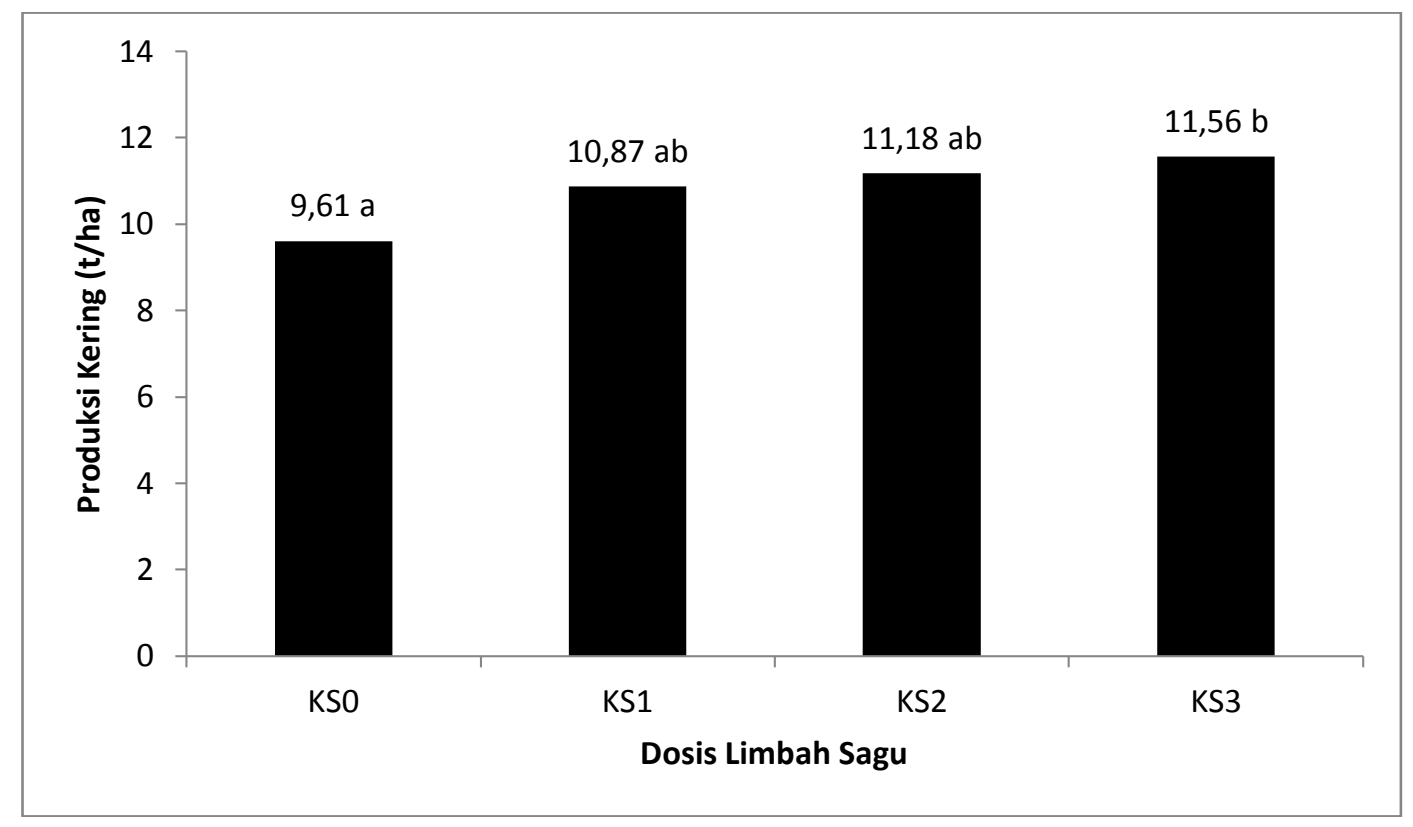

Gambar 1. Produksi bawang merah berdasarkan perlakuan dosis kompos limbah sagu umur 56 HST.

\section{Sifat Fisik Tanah}

Bobot isi tanah yang rendah menunjukkan tingginya porositas tanah, tanah kondisi gembur, dan meningkatnya kemampuan tanah menahan air. Bobot isi tanah yang rendah menunjukkan kandungan bahan organik tanah yang tinggi. Penumpukan bahan organik berupa kompos limbah sagu dibagian atas lapisan tanah yang lebih banyak berpengaruh 
terhadap bobot isi maupun kadar air tanah.

Rajiman et al. (2008) penambahan bahan organik berupa pupuk kandang 20 t/ha mampu menurunkan bobot isi tanah.

Tabel 2. Bobot isi tanah pada berbagai kedalaman tanah pada perlakuan kompos limbah sagu usai panen bawang merah

\begin{tabular}{|c|c|c|c|}
\hline \multirow{2}{*}{ Perlakuan } & \multicolumn{3}{|c|}{ Bobot Isi $(\mathrm{g} / \mathrm{cc})$} \\
\cline { 2 - 4 } & $0-5 \mathrm{~cm}$ & $0-10 \mathrm{~cm}$ & $0-15 \mathrm{~cm}$ \\
\hline KS 0 & 0,981 & 1,007 & 1,014 \\
KS 1 & 0,970 & 0,983 & 1,001 \\
KS 2 & 0,965 & 0,983 & 0,999 \\
KS 3 & 0,920 & 0,964 & 0,998 \\
\hline
\end{tabular}

Tabel 2 menunjukkan bahwa makin tebal lapisan tanah maka lapisan tanah tersebut kondisi bobot isi tanah semakin meningkat. Bobot isi yang meningkat dibagian bawah lapisan tanah umumnya disebabkan kandungan bahan organik rendah, kurangnya agregasi dan penetrasi akar, dan pemadatan yang disebabkan beban berat lapisan diatasnya (Brady 1990). Selain itu tanah-tanah berpasir banyak mengandung pori-pori makro sehingga sulit menahan air (Hardjowigeno 2003). Pemberian bahan organik dan konsentrasi cacing tanah mampu memperbaiki sifat fisik, kimia, dan biologi tanah. Zulfadli et al. (2012) hal ini diduga bahwa dengan pemberian bahan organik dan keberadaan cacing tanah maka tanah lebih gembur karena cacing tanah membuat liang di dalam tanah.

Kondisi kadar air tanah pada lapisan bedengan bawang merah pada perlakuan kompos limbah sagu menunjukkan bahwa, pemberian kompos limbah sagu semakin tinggi menunjukkan kadar air tanah berdasarkan berat (Tabel 3) maupun berdasarkan Volume (Tabel 4) meningkat. Hal ini menunjukkan penambahan bahan organik kompos limbah sagu di lapisan olah meningkatkan kemampuan tanah menahan air.

Tabel 3. Kadar air tanah berdasarkan berat pada berbagai kedalaman tanah pada perlakuan kompos limbah sagu usai panen bawang merah

\begin{tabular}{|c|c|c|c|}
\hline \multirow{2}{*}{ Perlakuan } & \multicolumn{3}{|c|}{ Kadar Air Tanah Berdasarkan Berat (\%) } \\
\cline { 2 - 4 } & $0-5 \mathrm{~cm}$ & $0-10 \mathrm{~cm}$ & $0-15 \mathrm{~cm}$ \\
\hline KS 0 & 23,970 & 23,367 & 25,619 \\
KS 1 & 28,799 & 25,555 & 25,624 \\
KS 2 & 24,399 & 24,558 & 26,423 \\
KS 3 & 24,377 & 24,448 & 26,266 \\
\hline
\end{tabular}


Tabel 4. Kadar air tanah berdasarkan volume pada berbagai kedalaman tanah pada perlakuan kompos limbah sagu usai panen bawang merah

\begin{tabular}{|c|c|c|c|}
\hline \multirow{2}{*}{ Perlakuan } & \multicolumn{3}{|c|}{ Kadar Air Tanah Berdasarkan Volume (\%) } \\
\cline { 2 - 4 } & $0-5 \mathrm{~cm}$ & $0-10 \mathrm{~cm}$ & $0-15 \mathrm{~cm}$ \\
\hline KS 0 & 14,752 & 19,333 & 22,895 \\
KS 1 & 22,339 & 23,547 & 25,774 \\
KS 2 & 23,551 & 24,232 & 26,320 \\
KS 3 & 28,354 & 25,309 & 26,493 \\
\hline
\end{tabular}

Penambahan kompos limbah sagu juga memberikan pengaruh terhadap porositas tanah, semakin meningkat pemberian bahan organik berupa kompos limbah sagu maka terlihat porositas makin meningkat (Tabel 5).

Hal ini terkait dengan sifat bahan organik di dalam tanah yang mampu berinteraksi dengan partikel tanah dan memberikan agregasi yang baik pada partikel-partikel tanah. Peningkatan bahan organik di dalam tanah memberikan pengaruh tanah makin gembur sehingga ruang pori makro maupun mikro mampu diisi baik oleh udara maupun air.

Tabel 5. Porositas tanah berdasarkan volume pada berbagai kedalaman tanah pada perlakuan kompos limbah sagu usai panen bawang merah

\begin{tabular}{|c|c|c|c|}
\hline \multirow{2}{*}{ Perlakuan } & \multicolumn{3}{|c|}{ Porositas Tanah(\%) } \\
\cline { 2 - 4 } & $0-5 \mathrm{~cm}$ & $0-10 \mathrm{~cm}$ & $0-15 \mathrm{~cm}$ \\
\hline KS 0 & 62,981 & 61,983 & 61,737 \\
KS 1 & 63,396 & 62,889 & 62,227 \\
KS 2 & 63,583 & 62,895 & 62,308 \\
KS 3 & 65,291 & 63,619 & 62,350 \\
\hline
\end{tabular}

\section{Populasi Cacing Tanah}

Cacing tanah mampu berkembang biak dengan baik jika tersedia bahan organik yang cukup sebagai makanannya.
Nampak bahwa pemberian kompos limbah sagu semakin meningkat, populasi cacing tanah yang ditemukan makin meningkat pula (Tabel 6).

Tabel 6. Jumlah cacing tanah pada berbagai kedalaman tanah pada perlakuan kompos limbah sagu usai panen bawang merah

\begin{tabular}{|c|c|c|c|}
\hline \multirow{2}{*}{ Perlakuan } & \multicolumn{3}{|c|}{ Jumlah Cacing Tanah (ekor/petak) } \\
\cline { 2 - 4 } & $0-5 \mathrm{~cm}$ & $0-10 \mathrm{~cm}$ & $0-15 \mathrm{~cm}$ \\
\hline KS 0 & 96 & 266 & 309 \\
\hline
\end{tabular}




\begin{tabular}{|c|c|c|c|}
\hline KS 1 & 160 & 352 & 384 \\
KS 2 & 437 & 693 & 779 \\
KS 3 & 480 & 981 & 1.077 \\
\hline
\end{tabular}

Pada perlakuan KS 0 yaitu tanpa pemberian kompos limbah sagu di lapisan 0-5 cm hanya ditemukan 96 ekor/petak, namun pada KS 3 populasi cacing tanah meningkat mencapai 480 ekor per petak. Bahkan pada kedalaman 0-15 cm dari 309 ekor/petak ada KS 0 menjadi 1.077 ekor/petak pada KS 3. Menurut Baker et al. (1992) kandungan bahan organik di dalam tanah merupakan salah satu faktor yang mendukung banyaknya populasi cacing tanah.

\section{KESIMPULAN}

1. Pemberian kompos limbah sagu pada dosis tinggi memberikan pengaruh nyata terhadap produksi kering bawang merah varietas Tajuk.

2. Pemberian kompos limbah sagu pada lahan tanaman bawang merah memperbaiki sifat fisik tanah yaitu menurunkan bobot isi tanah, meningkatkan kadar air tanah, serta meningkatkan porositas tanah.

3. Pemberian kompos sagu semakin tinggi memberikan dampak terhadap makin banyaknya jumlah cacing tanah yang ditemukan.

\section{DAFTAR PUSTAKA}

Aliudin, A.A., Asandhi dan B. Jaya. 1990. Pengujian varietas bawang merah (Allium ascalonicum) di dataran rendah Pulau Jawa. Bul. Penel. Hort. 19(3):44-47.

Baker, G., J. Buckerfielsd, R.G. Gardner, R. Merry and D. Doube. 1992. The abudance and diversity of earthworms in pasture soils in the fleurieu Peninsula, South Australia. Soil Biol. Biochem. 24(12):13891395.

Budianto, A., Ngawit, dan Sudika. 2009. Keragaman genetik beberapa sifat dan seleksi klon berulang sederhana pada tanaman bawang merah kultivar Ampenan. Crop Agro. 2(1):28-38.

Brady, N.C. 1990. The nature and properties of soils. Tenth Edition. Macmillan Publishing. Company. New York.

Firmansyah, M.A., dan A. Anto. 2013. Teknologi budidaya bawang merah lahan marjinal di luar musim. Kantor Perwakilan Bank Indonesia Provinsi Kalimantan Tengah.

Firmansyah, I. Liferdi, N. Khariyatun, dan M.P. Yufdi. 2015. Pertumbuhan dan hasil bawang merah dengan aplikasi pupuk organik dan pupuk hayati pada tanah alluvial. J. Hort. 25(2):133-141.

Hardjowigeno, S. 2003. Ilmu Tanah. Akedemika Pressindo. Edisi Baru. Jakarta.

Kusmana, R.S. Basuki, dan H. Kurniawan. 2009. Uji adaptasi lima varietas bawang merah asal dataran tinggi dan medium pada ekosistem dataran rendah Brebes. J. Hort. 19(3):281-286. 
Limbongan, J, dan A. Monde. 1999. Pengaruh penggunaan pupuk organik dan anorganik terhadap pertumbuhan dan produksi bawang merah kultivar Palu. J. Hort. 9(3):212-219.

Musaddad, T. Liana, M.S. Mokhtar, dan M.P. Yufdi. 2014. Uji adaptasi bawang merah pada saat musim hujan di Kalimantan Tengah. J. Hort. 24(2): 114-123.

Putrasamedja, S. 1990. Evaluasi beberapa kultivar bawang merah untuk musim penghujan di Brebes. Bul. Penel. Hort. 18(1):85-90.

Rajiman, P. Yudono, E. Sulistyaningsih, dan E. Hanudin. 2008. Pengaruh pembenah tanah terhadap sifat fisika tanah dan hasil bawang merah pada lahan pasir pantai Bugel Kabupaten Kulon Progo. Agrin.12(1)1:67-77.

Satsijati dan E. Koswara. 1993. Studi penerapan formulasi teknologi budidaya cabe dan bawang merah di lahan pasang surut. J. Hort. 3(1):13-20.

Sumarni, N, R. Rosliani, and R.S. Basuki. 2012. Respon pertumbuhan, hasil umbi, dan serapan hara NPK tanaman bawang merah terhadap berbagai dosis pemupukan NPK pada tanah Alluvial. J. Hort. 22(4):365-374.

Swasono. FDH. 2012. Karakteristik fisiologi toleransi tanaman bawang merah terhadap cekaman kekeringan di tanah pasir pantai. Jurnal AgriSains. 3(4):88-103.

Syahtria, I., Sampoerna, dan Wardati. 2016. Pengaruh kompos limbah sagu terhadap tanaman kelapa sawit Elaeis guineensis Jagcq. Di pembibitan utama. Jom Faperta 2(3):1-8.

Zulfadli, Muyassir, dan Fikrinda. 2012. Sifat tanah terkompaksi akibat pemberian cacing tanah dan bahan organik. J. Manajemen Sumberdaya Lahan. 1(1):54-61. 